\title{
Treatment research
}

\section{The aging mind: neuroplasticity in response to cognitive training}

Denise C. Park, PhD; Gérard N. Bischof, DiplPsy

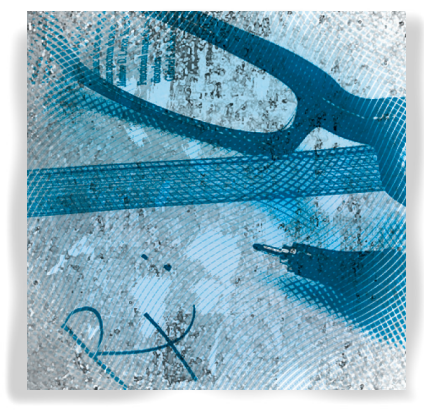

Is it possible to enhance neural and cognitive function with cognitive training techniques? Can we delay age-related decline in cognitive function with interventions and stave off Alzheimer's disease? Does an aged brain really have the capacity to change in response to stimulation? In the present paper, we consider the neuroplasticity of the aging brain, that is, the brain's ability to increase capacity in response to sustained experience. We argue that, although there is some neural deterioration that occurs with age, the brain has the capacity to increase neural activity and develop neural scaffolding to regulate cognitive function. We suggest that increase in neural volume in response to cognitive training or experience is a clear indicator of change, but that changes in activation in response to cognitive training may be evidence of strategy change rather than indicative of neural plasticity. We note that the effect of cognitive training is surprisingly durable over time, but that the evidence that training effects transfer to other cognitive domains is relatively limited. We review evidence which suggests that engagement in an environment that requires sustained cognitive effort may facilitate cognitive function.

๑ 2013, LLS SAS Dialogues Clin Neurosci. 2013;15:109-119.

\author{
Introduction
}

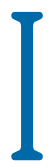

$t$ is well-documented by scientists and wellrecognized by the public that, as people age, they experience some diminishment of cognitive abilities. At some point, for many older adults, the decline becomes sufficiently serious that they are no longer able to live independently and manage their lives. Of course, when individuals decline cognitively to the point of inability to manage, they are experiencing significant neuropathology in the form of some type of dementia or other neurological disorder. The loss of the ability to live independently is one of the greatest fears adults express when considering old age. ${ }^{1}$ Based on the public's recognition and fear of pathological age-related cognitive decline, the issue of whether one can combat this decline has become a highly salient issue. A casual perusal of print, electronic, and broadcasting media would seem to give reason for optimism. Pills and elixirs are guaranteed to keep the brain healthy and sharp. Brain-training programs promise even more-these programs are purported to enhance and "rewire" the brain to make it better than ever. There are popular books with amazing titles that promise to reveal the simple secrets of improv-

Keywords: neuroplasticity; scaffolding; cognitive training; cognitive reserve; engagement

Author affiliations: The Center for Vital Longevity, School of Brain and Behavioral Sciences, University of Texas at Dallas, Texas, USA

Address for correspondence: Denise C. Park, PhD, Center for Vital Longevity, 1600 Viceroy Drive Suite 800, University of Texas at Dallas, Dallas, TX 75235, USA

(e-mail: denise@utdallas.edu) 


\section{Treatment research}

ing the mind and preventing dementias, including Alzheimer's disease. Nearly all of these claims are, at best, overly optimistic, and, at worst, blatant charlatanism. Nevertheless, the public's keen interest in this topic is matched by that of scientists, who have become deeply engaged in understanding how to improve the aging mind, or at least prevent its decline into dementia. ${ }^{2,3}$ In order to improve cognitive function, the aging brain must have plasticity - that is, the ability to change structure or function in a sustained manner in response to some type of external stimulation. In the present paper, we will consider what we mean by plasticity, and whether behavioral interventions designed to improve function of the aging brain have been successful.

Most studies that have conducted interventions on older adults have focused on training some type of cognitive skill through practice, and, at the end of a training period, measuring improvement. The improvement is typically behavioral (eg, improved working memory capacity $\left.{ }^{4-6}\right)$ but there are some studies that focus on actually changing neural activity or increasing neural tissue with training. ${ }^{5,7}$ Most studies also consider whether the observed improvement "transfers" to other tasks. ${ }^{5,8}$ Finally, some studies consider how long adults are able to maintain the trained improvement over time. In this paper, we will first discuss some basic issues associated with the topic of neuroplasticity in older adulthood, and what must be considered when evaluating the likelihood that a training intervention is actually helpful. Then we will review studies that have shown some evidence for improving both cognitive function and provide evidence for the neural substrate underlying the improvement. We will finally consider the impact of lifestyle factors (exercise and/or engagement) in maintaining and facilitating cognitive function in older adults. Finally, we will close with recommendations for future research.

\section{Improving function versus minimizing loss}

One issue that we feel does not get enough attention is the role that cognitive training and interventions play over the short and long term. Most studies are focused on showing an improvement in cognitive function immediately or a few weeks after training, relative to some appropriate control group. However, it is important to recognize that the normal course of aging is one of decline in many core cognitive abilities (commonly referred to as fluid intelligence), including speed of pro- cessing, working memory, long-term memory, and reasoning. ${ }^{9}$ Figure 1 presents evidence that all of these core abilities show age-related decline, even in a highly educated lifespan sample, while knowledge (crystallized intelligence) remains invariant, or even increases with age. Given the data presented in Figure 1, we suggest that the focus of cognitive training and other interventions should be on slowing cognitive aging. The Alzheimer's Association estimates that if the onset of Alzheimer's disease could be delayed by 5 years due to successful interventions, this would result in a $50 \%$ decrease in Alzheimer's diagnoses..$^{10}$ Moreover, many older adults are interested in staying in the work force past traditional retirement age. Participation in the work force for most adults would require that they maintain cognitive ability. Thus, slowing decline for this group could be very meaningful, as it would allow them to continue to work. There are few studies that have examined the effects of interventions over a period of years. Nevertheless, the ability to find effective techniques that will slow the process of aging is almost certainly more important than the demonstration of short-term improvements in cognitive function. Slowing decline of the aging mind is both an economic and quality of life issue that is central to controlling spiraling health costs as well as providing for the emotional well-being of both older adults and their families.

\section{How can the brain protect itself from decline?}

The concept of some type of neural or cognitive pool of resources that protects against age-related cognitive decline has been an important idea in both the cognitive and neural aging literature. The basic notion emerged from evidence that there are substantial individual differences in the rate that people evidence cognitive aging, and there must be some mechanism that accounts for these differences. To address this issue, Baltes and Baltes ${ }^{11}$ proposed the construct of "reserve capacity," suggesting that older adults were able to maintain cognitive function by drawing on a pool of resources that mitigated aging effects. Interestingly, the earliest neuroimaging research on older adults provided clear evidence that older adults showed increased contralateral hemispheric recruitment in right frontal regions for both working memory ${ }^{12}$ and episodic encoding, ${ }^{13}$ supporting the notion of compensation and neural reserve. This increased bilateral recruitment in frontal cortex that 
occurred across multiple cognitive tasks was interpreted to indicate that the enhanced neural activity of old adults operated to maintain cognitive function.

The scaffolding theory of aging and cognition (STAC) ${ }^{14}$ provides a theoretical model for the causes and consequences of age-related compensatory neural activity. STAC posits that cognitive function in older adults can be understood in terms of the magnitude of neural insults that the brain has sustained (both structural and functional) as well as the compensatory neural activities ("scaffolding") that operate to maintain cognitive behavior. According to this model, scaffolding is conceptualized as the recruitment of additional circuitry that shores up declining brain function that has become noisy, inefficient, or both. The pervasive finding of increased prefrontal activation in older adults across many different cognitive tasks reflects the engagement of compensatory scaffolding. The scaffolding is a direct response to the neural insults of aging which include vol- umetric shrinkage of brain structures, ${ }^{15}$ white matter degradation, ${ }^{16}$ and amyloid deposition, ${ }^{17}$ as well as functional decline in neural activities associated with dedifferentiation of ventral visual cortex ${ }^{18,19}$ poor modulation of default network activity, ${ }^{20}$ and declining activity in the hippocampus. ${ }^{21,22}$ Effective compensatory activation in response to this degradation mitigates age-related decline in cognition. Importantly, STAC also provides for the possibility that cognitive training or sustained engagement in a novel task or environment, as well as exercise, can enhance the development of compensatory scaffolding, so that the ability to increase scaffolding as a result of cognitive training confers protection on cognitive function.

A related view that has emerged from the imaging literature is that of cognitive reserve. ${ }^{23}$ The cognitive reserve model suggests that there are specific experiences and behaviors that confer protection from age-related decline. Examples of behaviors that may create reserve

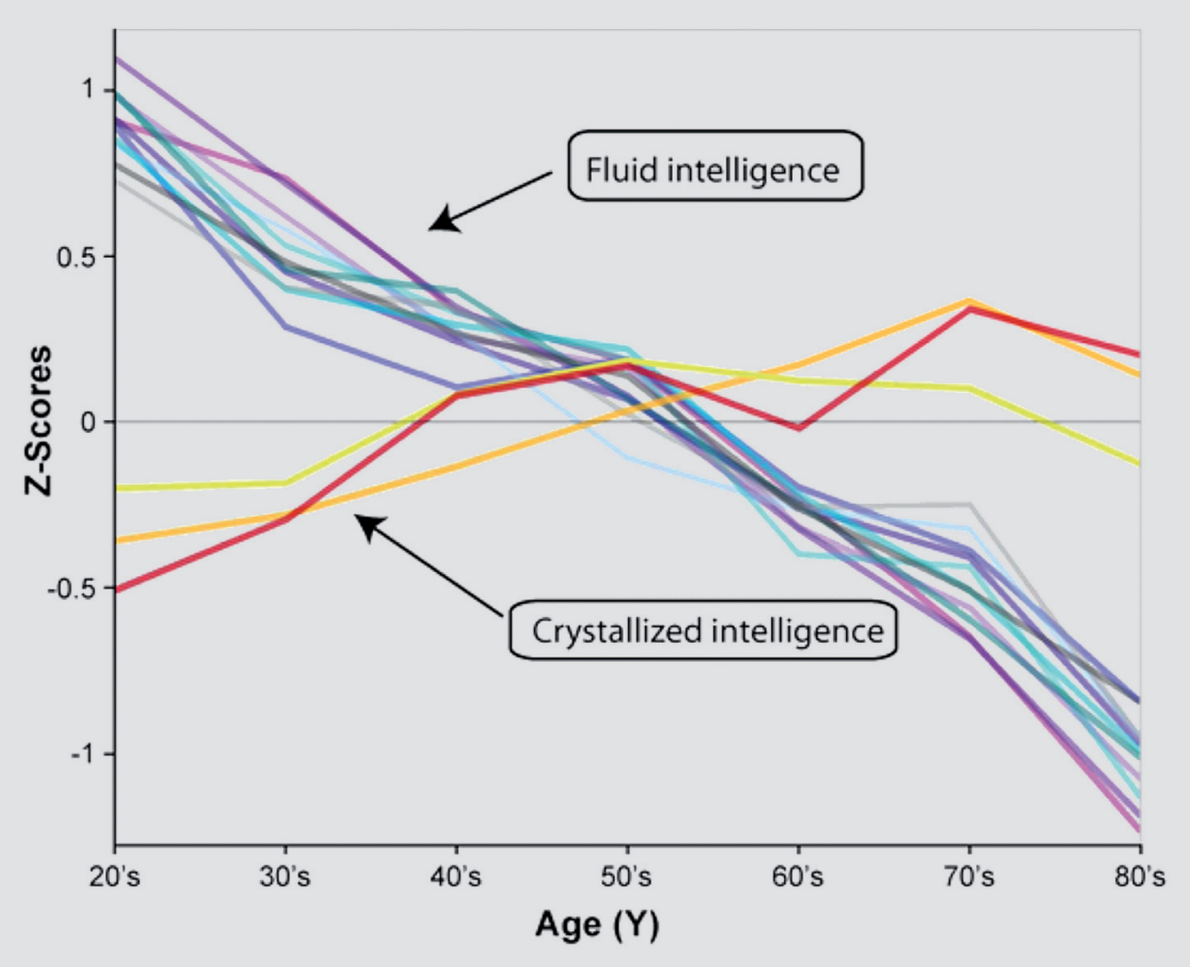

Speed of Processing

— Digit Symbol

- Letter Comparison

- Pattern Comparison

Working Memory

- Letter Rotation

- Line Span

Computation Span

Reading Span

Long-Term Memory Benton

- Rey

Cued Recall

- Free Recall

World Knowledge Shipley Vocabulary Antonym Vocabulary

- Synonym Vocabulary

Figure 1. Cross-sectional aging data adapted from ref 9 showing behavioral performance on measures of speed of processing (ie, Digit Symbol, Letter Comparison, Pattern Comparison), working memory (ie, Letter rotation, Line span, Computation Span, Reading Span), Long-Term Memory (ie, Benton, Rey, Cued Recall, Free Recall), and world knowledge (ie, Shipley Vocabulary, Antonym Vocabulary, Synonym Vocabulary). Almost all measures of cognitive function (fluid intelligence) show decline with age, except world knowledge (crystallized intelligence), which may even show some improvement. 


\section{Treatment research}

include education, high literacy, engaging work, and maintenance of an active, engaged lifestyle in late adulthood. ${ }^{24,25}$ All of these experiences appear to delay progression towards Alzheimer's disease, although, without experimental studies, the causal component is unclear (eg, do people high in reserve stay in the workforce or does workforce participation create reserve?). Stern ${ }^{26}$ distinguishes between neural reserve and neural compensation. Reserve is essentially an increased supply of neural resources created as a result of experiences, whereas neural compensation is the ability to draw more effectively and efficiently on networks.

\section{Can the brain actually improve as a result of experience?}

Although the findings in the literature are sparse, there is a range of evidence suggesting that the older brain has considerable plasticity. Probably the most compelling data comes from stroke patients who have sustained permanent damage to their brain in specific areas as a result of neural bleed or blood clot. Despite very significant damage that has led to loss of behavioral function, stroke patients show dramatic recovery with sustained therapy. ${ }^{27}$ This change in function can only be due to plastic changes in brain function, where new parts of the brain take over functions performed by areas that have been damaged. The plasticity evidenced in stroke patients is quite amazing, and indicates that the aging brain is very capable of neural reorganization. One important thing to note about stroke patients are that they undergo many hours of intense therapy to regain function, and that this training is in domains that greatly facilitate function in everyday life. Thus, the environment maintains and supports gains in improvement after stroke, as patients must have communication and mobility skills if they are to maintain independence in everyday life. It is also important to recognize that a part of the stroke patient's brain has literally shut down, and this extreme condition forces the brain to manifest any plasticity that is available to restore function, when it may not do so under normal conditions.

Healthy adults, on the other hand, may not have the ability to consciously draw upon unused parts of the brain to enhance cognitive function. Much remains to be understood as to how much cognitive training or other cognitive interventions can enhance function, but it does seem clear, based on stroke patients, as well as data from animal studies, ${ }^{28}$ that the potential of brain reorganization does occur even in late adulthood. Nevertheless, the conditions under which healthy older brains reorganize in an adaptive matter to enhance cognitive function are poorly understood.

In line with the notion that contextual press or demand is an important element of accessing and utilizing any neural plasticity that exists in the aging brain, is the concept of a sustained mismatch between a person's desired cognitive state or goal and the demands of the environment. ${ }^{29}$ It is only when an individual experiences substantial and sustained demands on their cognitive system that plasticity will manifest itself. An older adult who, for example, must learn a demanding new route to visit his or her grandchildren in a new city might need to draw maximally upon attentional, task-switching, and working memory resources to complete this demanding drive on a complex highway system in traffic. This initial task requires flexibility; that is, deployment of the existing supply of resources to perform the novel task at hand. Plasticity would be manifested if this trip was successful, and the older adult began driving to many new places and ultimately developed significantly enhanced driving skills over a sustained period. This sustained novel activity might result in neural reorganization or even growth of neural structures associated with way-finding (much like the famed London cab driver study ${ }^{30}$ ), in which case plasticity would be manifested. Finally, we note that many of the cognitive demands associated with a demanding new drive could be diminished by using a navigational system, in which case, neither flexibility nor plasticity would be required, as the environmental support provided by the navigational system would result in a match between existing abilities and task demands. In a similar vein, Park et al ${ }^{31}$ suggest that cognitive change can only occur when a task or environment consistently makes demands on core cognitive processes like speed, working memory, episodic memory, and reasoning. Finally, it is important to recognize that there can be substantial individual differences in what comprises a demanding task or a challenging environment, and Park et $\mathrm{al}^{31}$ explicitly note the importance of novelty in effecting change. An older adult who was an accountant might not find it very demanding to learn how to manage a stock portfolio, but would be very challenged by learning to play a musical instrument. Past experiences, expertise, and cognitive status will all play important roles in understanding tasks that provide optimal challenge to 
an individual and have the potential to effect change in neural structure or function.

\section{What constitutes change?}

\section{Increases in neural volume}

There is tremendous debate about what constitutes evidence for neural plasticity. Perhaps the most unambiguous evidence is when training increases the thickness or volume of neural structure. It has been demonstrated that sedentary older adults who engage in aerobic exercise can delay shrinkage in prefrontal cortex, an area maximally sensitive to age-related volumetric shrinkage. ${ }^{32}$ In terms of cognitive interventions, actual gains in neural volume relative to a control group were demonstrated by Boyke et $\mathrm{al}^{33}$ in the mid temporal regions, hippocampus and nucleus accumbens, when older adults were trained to juggle for 90 days. These regions are associated with complex motor behaviors, so this finding was an important demonstration of plasticity in older adults. Importantly, however, the gains were not maintained after a 90-day period of non-juggling, providing important evidence that there are many constraints on plasticity, and that the familiar "use or lose it" adage was disappointingly relevant in this particular study. Other evidence shows that older men who played a demanding spatial navigational game every other day for 4 months exhibited stability of hippocampal volume over a 4-month period, whereas control subjects declined. ${ }^{34}$ Additionally, these trained subjects showed an increase in structural integrity of the hippocampus which was maintained when training ceased. Overall, however, the evidence that one can improve volume of neural structures through training is relatively sparse. The limited data available suggest that gains that are realized from a sustained training program most likely need to be maintained with continued performance. An important question is whether continuous improvement and challenge on a task is required to maintain gains, or whether mere maintenance of a high level of improved but asymptotic performance would be sufficient to preserve gains. It seems likely that it will be important for individuals to enjoy the tasks they are performing over the very long term so that the behavior can be sustained and gains maintained. This may be the greatest challenge associated with training the aging human brain. From a clinical perspective, daily "brain training" could become a boring and effortful task, such that gains realized might be offset by the negative consequences of performing a task that over time could become a dreaded obligation rather than a pleasurable and stimulating activity.

\section{Changes in neural activity}

A more common finding than volumetric increase is a change in neural activity with training. The change can be in the form of activation of new regions, or decreases or increases in neural activity in task related structures that were activated before the training. The neural differences between pretest and post-test can be quite hard to interpret, and may or may not reflect a fundamental change in brain function or organization. Noack et $\mathrm{al}^{35}$ argue that many changes in activation as a result of training reflect flexibility in deployment of resources due to strategy change rather than a manifestation of plasticity resulting in an increase in intrinsic neural or cognitive capacity. They argue that the rich knowledge base that accrues as we age provides an excellent mechanism for utilizing wisdom and knowledge to facilitate performance, rather than a true change in the neurocognitive system. They suggest that younger adults have more neural plasticity than old, and that the young are most likely to show an increase in intrinsic neural capacity with training, whereas the old are more likely to recognize gains due to flexibility in strategy use.

The expectation behind training is that it will improve cognitive capacity and thus increase neural efficiency by decreasing the demands a task makes on the neural system. If this is the case, one might expect that training would decrease neural activation on the trained task. Such a finding was reported by Brehmer et al. ${ }^{36}$ They trained older adults on a working memory task for 5 weeks and found that subjects who trained on the most demanding tasks (adaptive training) showed a decrease in activation in frontal, parietal, and occipital regions, which the authors suggested reflected improved neural efficiency and decreased resource utilization as a result of training.

On the other hand, there is a considerable body of literature suggesting that enhanced neural activity is facilitative for old adults, so it is also easy to imagine findings where training enhances neural activation and behavioral function in older adults. In line with this hypothesis, Nyberg et $\mathrm{al}^{7}$ reported that mnemonic training in older adults resulted in an increase in activations in 


\section{Treatment research}

occipito-parietal regions, but only for those who showed a training-related behavioral improvement. Young adults showed improvement in these regions as well, but also evidenced increases in frontal regions. Similarly, Carlson et $\mathrm{al}^{37}$ reported that older adults who were highly engaged in the Experience Corps intervention (a program where older adults engage in support and literacy activities for elementary teachers) showed an increase in prefrontal activity as well as an increase in executive function. Using a different approach, Mozolic et $\mathrm{al}^{38}$ examined changes in cerebral blood flow as a result of training. They reported that 6 weeks of attentional training in older adults resulted in an increase in cerebral blood flow to the prefrontal cortex during rest, combined with a decrease in distractibility.

The neurological literature on cognitive training is at an early stage, and results are varied and actually quite limited. It is difficult to predict whether training will increase or decrease neural activity, and how it might interact with age, as well as how durable effects are over time. It also is surprisingly difficult to assess whether any observed brain changes reflect a fundamental increase in neural capacity or merely a change in strategy. Lövdén et $\mathrm{al}^{39}$ suggest that specific strategy instructions operate to reduce performance differences between subjects because, in a sense, such instructions level the playing field so that old and young participants are more likely to use similar and optimal strategies. At the same time, Lövdén et $\mathrm{al}^{39}$ observed that sustained cognitive training that followed the strategy instructions operated to magnify differences between individuals, because there was considerable heterogeneity in the ability of participants to profit from the training - that is, there were significant plasticity differences between subjects. These joint manipulations of instruction and training provided an elegant demonstration of how one might begin to separate strategy effects from changes in actual neural capacity.

This brief discussion of the relationship between training effects and neural change highlights the complexity of the issues associated with training and neural function. Given the plethora of possibilities in findings, as well as the interpretations of those findings, associated with training, it would be wise for training studies that utilize neural measures to use training tasks that have been highly researched so that neural circuitry engaged by old and young is well understood. Moreover, a focus on studies with large participant pools, inclusion of a group that could replicate previous findings, and inclusion of long-term follow-up intervals will all enhance the quality of work and our understanding of the relationship among training, neural function, and behavioral improvement.

\section{Near versus far transfer}

One important aspect of training studies is whether the training results in broad changes in processing abilities that transfer to other unrelated tasks (so-called "far transfer") or whether it is only the trained ability that improves. ${ }^{40,41}$ This is in fact an age-old issue in the cognitive aging literature, dating back to early work done by Willis et $\mathrm{a}^{141}$ on the Seattle Longitudinal Study of Aging. It is clear from a raft of studies that older adults improve significantly on a trained task ${ }^{42}$ and that the training improvements in some cases are manifested for prolonged periods of time, even years later. ${ }^{43}$ Despite these encouraging findings, there is relatively little evidence that training induces a fundamental change in processes that transfer to everyday life. We do note that Willis et $\mathrm{al}^{43}$ reported that participants who were trained in reasoning in the ACTIVE trial ${ }^{42}$ reported less difficulty in instrumental activities of daily living 5 years later, ${ }^{43} \mathrm{a}$ finding which is indicative of both far transfer and improvement in everyday function, but this is an uncommon finding. Furthermore, in the same study, training in speed of processing and episodic memory did not yield significant improvements, and thus the mediating mechanism for the improvement in daily activities resulting from reasoning training is not clear. Nevertheless, the results are encouraging.

The concept of far transfer as a result of "brain training" is highly appealing and is absolutely fundamental to claims that for-profit enterprises make about their neural facilitation products. The basic premise of these products is that their use (that typically involves extended training on tasks that train core cognitive processes) will literally make a person smarter and that the training will lead to broad improvement in many mental activities. Until recently, there was not strong evidence that this far transfer occurred, typically because appropriate control groups were not employed, or claims by purveyors of products were not rigorously evaluated. Recent work on working memory training, however, has yielded provocative evidence for far transfer from training on a working memory task to improvement in gen- 
eral intelligence. ${ }^{8}$ Findings indicate that young adults who are consistently challenged to increase their working memory span in an n-back paradigm are able to do so with training. More importantly, those participants who improve on the n-back training task show a significant increase in general measures of fluid intelligence. Thus far, the effects have been limited to young adults and, more recently, to children who showed an improvement in working memory from the original training. ${ }^{44}$ The only neural study of "far transfer" of which we are aware was conducted by Dahlin et al. ${ }^{45}$ In this study, the researchers trained young and old on an updating task, a critical component of working memory function involving the ability to rapidly delete irrelevant information and integrate relevant information in working memory. When subjects were tested on a 3-back task, a related but different working memory task, they found young but not old showed transfer. Importantly, when the neural underpinnings of this effect were investigated, Dahlin et $\mathrm{al}^{5}$ reported that the trained updating task improved striatal function in young and that the striatal activation was shared by the 3-back transfer task. Importantly, older adults did not show striatal activity during training or during the transfer task. Thus, it appeared that striatal function was trained in young adults and the training transferred to other striatumbased tasks. This important result suggests that a neural process, rather than a task, was trained and that this is an effective mechanism for future training. ${ }^{1}$ We note as well that whether the transfer was "far" is arguable. Both trained and transfer task relied on the same neural circuitry and, although the tasks were different, both were tasks that tapped into working memory. Finally, the fact that the training was unsuccessful in older adults is a caveat regarding the difficulties that will be encountered in neural training in later adulthood. There is at present little evidence that cognitive training on a task will improve general cognitive ability in old adults, despite a plethora of claims in the media. Nevertheless, extant data for young suggest that it is not implausible that such findings could emerge as we learn more about the basis for transfer effects.

\section{Maintenance of gains}

There are a range of studies that have demonstrated that cognitive training in older adults has resulted in gains over time for periods ranging from 3 months to 5 years.
Mahncke et $\mathrm{a}^{46}$ trained participants extensively ( 1 hour per day for 8 to 10 weeks) on a series of computerized tasks designed to improve representational fidelity of language systems. Following training, subjects received a battery of neuropsychological tests and there was evidence that, despite no training specifically on memory, the training improved verbal memory on the Repeatable Battery for the Assessment of Neuropsychological Status (RBANS) ${ }^{47}$ Three months later, the participants showed an improvement in digit span forward scores relative to controls. These findings are interesting and provide some evidence for far transfer. It is unfortunate that the design of the study did not permit a second test of memory improvement at 3 months, and that a number of participants were initially at ceiling performance on the memory task, possibly limiting the impact of the intervention. A critical design feature of intervention studies is that the training and transfer tasks have sufficient range to accommodate the scores of both young and older adults. The tasks must have sufficient difficulty to challenge adults and avoid ceiling effects, but not be so difficult that floor is observed in the frailest adults or months after task performance. In a related study, Zelinski et $\mathrm{al}^{48}$ reported on a much larger sample (n $=487$ ) of older adults who received auditory language training similar to that of Mahncke et $\mathrm{al}^{46}$ or participated in control conditions. At 3-month follow-up after the language training, there was a significant improvement in tasks that were directly trained as well as in a memory composite score, but not in the RBANS memory task, as reported earlier by Mahncke et al. ${ }^{46}$ Overall, the results do provide some evidence for far transfer from auditory language training to a memory task as a result of training, but the findings are somewhat inconsistent across studies. As the authors note, it is both desirable and important to show some improvement in functional outcomes, and over longer periods of time. We also note that the Dahlin et $\mathrm{al}^{45}$ study discussed earlier reported that, although old adults did not show cognitive or neural facilitation on a transfer task after updating training, both young and old showed gains on the trained updating task. Of particular interest was the finding that older adults, when tested 18 months later, maintained gains that they demonstrated on the originally trained updating task.

Overall, there is a growing body of evidence suggesting that training gains can be maintained for long periods on the originally trained task, but that transfer effects are 


\section{Treatment research}

not easily demonstrated, particularly in older adults. Given these findings, perhaps the focus of training studies should be mainly on training skills and abilities that have pragmatic value and would be useful in everyday life. Cognitive training is time-consuming for the participant. If the primary gain to the trainee is that he or she becomes more efficient at the training task for a prolonged interval, the gain to the participant is slight. With more practical tasks, the time investments of both participants and staff are likely to lead to gains for the participant in their everyday life, even if they do not realize far transfer.

\section{Engagement as a cognitive intervention}

There are a number of studies that suggest that older adults who maintain an active lifestyle or who engage in a range of intellectual pursuits are diagnosed at later ages with Alzheimer's disease. ${ }^{49}$ In fact, there is com- pelling evidence that a high level of education confers protection against neurocognitive aging and decline ${ }^{26}$ and is a type of cognitive reserve. The problem with these large epidemiological studies is that the data are primarily correlational, and it is not entirely clear if maintaining an active mind and lifestyle offers protection against cognitive aging, or whether those who are protected tend to maintain an active lifestyle. Nevertheless, the notion that staying mentally active confers protection against cognitive decline is pervasive and best represented by the frequently invoked adage of "use it or lose it." It is surprising that there is relatively little research that provides a careful test of this statement, and that is largely because it is quite difficult to study experimentally the effects of an engaged lifestyle. There are a few studies that have addressed this issue and all have shown positive but relatively limited effects. The Experience Corps Project ${ }^{37}$ examined the cognitive benefits of older adults working with teachers in pro-

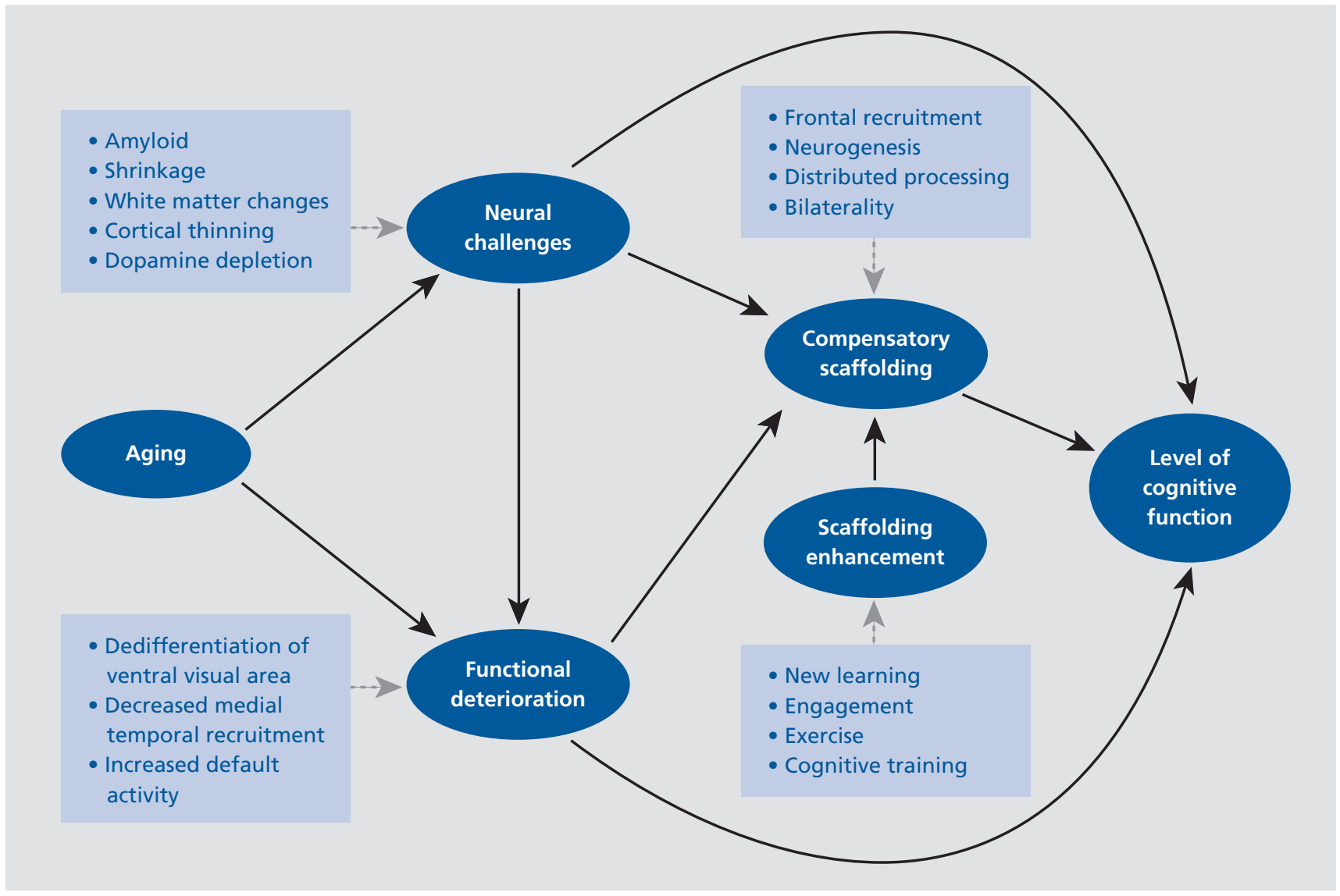

Figure 2. A conceptual model of the scaffolding theory of aging and cognition (STAC). 
grams to train literacy and provide educational assistance to young children. The program has shown that participation yielded cognitive, social, and health benefits to older adults, while at the same time giving back to the community ${ }^{50}$ In addition, there is some evidence that participation increased neural activation in prefrontal cortex along with behavioral performance on executive function tasks. Another project that examines the role of sustained engagement on cognition is the Odyssey of the Mind Project. ${ }^{51}$ In this study, participants regularly participated in group problem-solving activities for several months with a culminating event that required elaborate team-based performance to present solutions to complex, ill-defined problems. In an initial study, Odyssey participants realized gains in fluid ability from pretest to post-test,${ }^{53}$ and, in a later study, showed an enhancement in the personality trait of openness to experience. ${ }^{54} \mathrm{In}$ recent work in our own laboratory, the Synapse project ${ }^{55}$ required that older adults participate in a demanding new learning task 15 hours a week for 3 months. Participants were immersed in what Park et $\mathrm{al}^{31}$ described as "productive engagement"-new learning that requires consistent engagement of working memory, motor skills, reasoning, and social challenge. Participants in productive engagement conditions learned quilting, digital photography, or both. Other participants were randomly assigned to "receptive engagement" conditions - situations that involved stimulating social activities or use of existing knowledge but relatively little new learning. Results indicated that participants in the productive but not receptive engagement conditions showed improved episodic memory performance, a finding similar to the results from the Experience Corps Project. ${ }^{37}$ Although much more experimental work is needed on the issue of engagement, there is a small but promising body of literature which suggests that modest amount of cognitive gains can be realized by engagement in tasks that demand sustained cognitive effort. The engagement issue is an important one because engaging activities are intrinsically satisfying and can be sustained indefinitely with considerable pleasure. Unlike cognitive training that relies on computer training and may deprive individuals of social engagement and pursuit of satisfying activities, immersion in a social learning environment has the potential to confer cognitive protection while meeting basic psychological needs for social interactions and purpose in life.

\section{Summary and conclusions}

There is some evidence that the aging brain is malleable and that cognitive function can be facilitated through cognitive training or engagement in demanding tasks that provide a sustained cognitive challenge. Unfortunately, the most durable effects observed in old adults are gains on the trained task, with only limited evidence that "far transfer" (ie, improvement on an array of tasks that share similarity in processes but not content to the trained task) is possible. Nevertheless, the persistence of training effects over a period of years is both impressive and somewhat unexpected. Despite remarkable tools to examine neural structure and function in the aging brain, a great deal of work needs to be done to understand whether changes in neural function are indicative of neural plasticity or merely represent shifts in strategy. Evidence suggests that older adults show less neuroplasticity than younger subjects, and we argue that interventions that successfully delay agerelated cognitive decline will yield greater benefits than short-term facilitation of cognition. An important aspect of cognitive enhancement techniques that is not considered sufficiently is how enjoyable the activities to be performed are. We argue that engagement in challenging leisure activities that activate core cognitive processes such as working memory, episodic memory, and reasoning may ultimately prove to be more effective than computer-based training techniques due to the ability to of older adults to sustain interesting leisure activities indefinitely. One of the greatest research challenges facing this domain of research is to demonstrate that cognitive training results in meaningful gains in everyday life or delays onset of Alzheimer's disease or other neurological disorders. Another area of particular importance is understanding the meaning of neural change and what type of neural change represents enhancement (eg, decreased activity could represent enhanced neural efficiency or insufficient neural engagement). The field would greatly profit from evidence for replicability of important findings. Claims that older adults can greatly improve their intellectual capacity or prevent Alzheimer's disease through "brain training" appear, at this time, to be overstated. Nevertheless, there is sufficient promise in results that continued investigation and the hope for a clearer understanding of mechanisms underlying observed effects is warranted.

Acknowledgments: This work was supported by the National Institute on Aging at the National Institutes of Health (5R37AG-006265-25 and (NIA grant 5R01AG026589-05). 


\section{Treatment research}

\section{El envejecimiento de la mente: la neuroplasticidad en respuesta al entrenamiento cognitivo}

¿Es posible mejorar la función neuronal y cognitiva con las técnicas de entrenamiento cognitivo? ¿Podemos retrasar con intervenciones la disminución de la función cognitiva relacionada con la edad y evitar la Enfermedad de Alzheimer? ¿Tiene realmente un cerebro envejecido la capacidad de cambiar en respuesta a la estimulación? En este artículo se revisa la neuroplasticidad del cerebro que envejece, es decir, la posibilidad de este órgano de aumentar su capacidad en respuesta a la experiencia mantenida. Se argumenta que, aunque existe un cierto deterioro neuronal que ocurre con la edad, el cerebro tiene la capacidad de aumentar la actividad neuronal y desarrollar una estructura neuronal para regular la función cognitiva. Se sugiere que los aumentos del volumen neuronal en respuesta al entrenamiento o la experiencia cognitiva constituyen un claro indicador de cambio, pero que los cambios en la activación en respuesta al entrenamiento cognitivo pueden ser una evidencia de cambio de estrategia más que un indicador de plasticidad neuronal. Se menciona que el efecto del entrenamiento cognitivo sorprendentemente perdura a lo largo del tiempo, pero es relativamente limitada la evidencia que existe respecto a que los efectos del entrenamiento se puedan trasladar a otros dominios cognitivos. Se revisa la evidencia que sugiere que la participación en un ambiente que requiere de un esfuerzo cognitivo sostenido puede facilitar el funcionamiento cognitivo.

\section{REFERENCES}

1. Lustig C, Shah P, Seidle R, Reuter-Lorenz, P. Aging, training, and the brain and future directions. Neuropsychol Rev. 2009;19:504-522.

2. Park DC, Bischof, GN. Neuroplasticity, aging, and cognitive function. In: Schaie KW, Willis SL, eds. Handbook of the Psychology of Aging. San Diego, CA: Academic Press; 2011:109-117.

3. Clarity Web site. Aging in place in America. Available at: http://www.clarityproducts.com/. Published August 20, 2007. Accessed December 3, 2008. 4. Buschkuehl M, Jaeggi SM, Hutchison S, et al. Impact of working memory training on memory performance in old-old adults. Psychol Aging. 2008;23:743-753.

5. Dahlin E, Neely AS, Larsson A, Bäckman L, Nyberg L. Transfer of learning after updating training mediated by the striatum. Science. 2008;320:1510-1512.

6. Li SC, Schmiedek F, Huxhold O, Röcke C, Smith J, Lindenberger U. Working memory plasticity in old age: transfer and maintenance. Psychol Aging. 2008;23:731-742

\section{L'intellect du sujet âgé : \\ la neuroplasticité en réponse à l'entraînement cognitif}

Les techniques d'entraînement cognitif peuventelles améliorer les fonction neurales et cognitives? Pouvons-nous retarder le déclin des fonctions cognitives lié à l'âge et éviter la maladie d'Alzheimer ? Un cerveau âgé peut-il vraiment changer en réponse à une stimulation ? Nous étudions dans cet article la neuroplasticité du cerveau vieillissant, c'est-à-dire le potentiel du cerveau d'augmenter sa capacité de réponse à une expérience prolongée. Nous pensons que le cerveau, en dépit d'une certaine détérioration liée à l'âge, peut augmenter son activité neurale et développer un échafaudage neural pour réguler la fonction cognitive. L'augmentation du volume neural en réponse à l'expérience ou à l'entraînement cognitif nous semble être un bon indicateur de modification ; cependant, les changements dans l'activation de la réponse à l'entraînement cognitif seraient plus une preuve de changement de stratégie qu'un indicateur de plasticité neurale. Nous observons que l'effet de l'entraînement cognitif est, de façon surprenante, durable dans le temps, mais que les arguments en faveur du transfert de ces effets sur d'autres domaines cognitifs sont assez limités. Nous passons en revue les preuves suggérant qu'une implication dans un environnement demandant un effort cognitif prolongé pourrait faciliter la fonction cognitive.

7. Nyberg L, Sandblom J, Jones S, et al. Neural correlates of trainingrelated memory improvement in adulthood and aging. Proc Natl Acad Sci. 2003;100:13728-13733.

8. Jaeggi SM, Buschkuehl M, Jonides J, Perrig WJ. Improving fluid intelligence with training on working memory. Proc Natl Acad Sci. 2008;105:6829-6833.

9. Park DC, Lautenschlager G, Hedden T, Davidson NS, Smith AD, Smith PK. Models of visuospatial and verbal memory across the adult life span. Psychol Aging. 2002;17:299-320.

10. Alzheimer's Association Web site. Available at: http://www.alz.org/alzheimers_disease_trajectory. Published May 2010. Accessed November 25, 2012.

11. Baltes $P$, Baltes M. Psychological perspectives on successful aging: The model of selective optimization with compensation. In: Baltes P, Baltes M. Successful Aging: Perspectives from the Behavioral Sciences. Cambridge, UK: Press Syndicate of the University of Cambridge;1990:1-35.

12. Reuter-Lorenz PA, Jonides J, Smith EE, et al. Age differences in the frontal lateralization of verbal and spatial working memory revealed by PET. J Cogn Neurosci. 2000;12:174-187. 
13. Cabeza R, Anderson ND, Locantore JK, McIntosh AR. Aging gracefully: compensatory brain activity in high-performing older adults. Neurolmage. 2002;17:1394-1402.

14. Park DC, Reuter-Lorenz PA. The adaptive brain: aging and neurocognitive scaffolding. Annu Rev Psychol. 2009;2:173-196.

15. Raz N, Lindenberger U, Rodrigue KM, et al. Regional brain changes in aging healthy adults: General trends, individual differences and modifiers. Cereb Cortex. 2005;15:1679-1689.

16. Raz N, Rodrigue KM. Differential aging of the brain: patterns, cognitive correlates and modifiers. Neurosci Biobehav Rev. 2006;30:730-748.

17. Rodrigue KM, Kennedy KM, Devous MD Sr, et al. $\beta$-Amyloid burden in healthy aging: regional distribution and cognitive consequences. Neurology. 2012;78:387-395.

18. Park DC, Polk TA, Park R, Minear M, Savage A, Smith MR. Aging reduces neural specialization in ventral visual cortex. Proc Natl Acad Sci. 2004; 101:13091-13095.

19. Carp J, Park J, Polk TA, Park DC. Age differences in neural distinctiveness revealed by multi-voxel pattern analysis. Neurolmage. 2010;15;56:736743.

20. Andrews-Hanna JR, Snyder AZ, Vincent JL, et al. Disruption of largescale brain systems in advanced aging. Neuron. 2007; 56:924-935.

21. Gutchess AH, Welsh RC, Hedden T, et al. Aging and the neural correlates of successful picture encoding: frontal activations compensate for decreased medial-temporal activity. J Cogn Neurosci. 2005;17:84-96.

22. Park DC, Gutchess AH. The cognitive neuroscience of long term memory and aging. In: Cabeza R, Nyberg L, Park D, eds. A Handbook of Cognitive Neuroscience of Aging. New York, NY: Oxford University Press; 2000.

23. Stern $Y$. What is cognitive reserve? Theory and research application of the reserve concept. J Int Neuropsychol Soc. 2000;8:448-460.

24. Meng $X, D^{\prime}$ Arcy C. Education and dementia in the context of the cognitive reserve hypothesis: a systematic review with meta-analyses and qualitative analyses. PLoS One. 2012;7:e38268.

25. Tucker AM, Stern Y. Cognitive reserve in aging. Curr Alzheimer Res. 2011;8:354-360.

26. Stern Y. Cognitive reserve in ageing and Alzheimer's disease. Lancet Neurol. 2012;11:1006-1012.

27. Ramanathan D, Conner JM, Tuszynski MH. A form of motor cortical plasticity that correlates with recovery of function after brain injury. Proc Natl Acad Sci U S A. 2006;103:11370-11375.

28. Murphy $\mathrm{TH}$, Corbett $\mathrm{D}$. Plasticity during stroke recovery: from synapse to behaviour. Nat Rev Neurosci. 2009;10:861-872.

29. Lövdén M, Bäckman L, Lindenberger U, Schaefer S, Schmiedek F. A theoretical framework for the study of adult cognitive plasticity. Psychol Bull. 2010;136:659-676.

30. Maguire EA, Gadian DG, Johnsrude IS, et al. Navigation-related structural change in the hippocampi of taxi drivers. Proc Natl Acad Sci. 2000;97:4398-4403.

31. Park DC, Gutchess AH, Meade ML, Stine-Morrow, EA. Improving cognitive function in older adults: nontraditional approaches. J Gerontol $B$ Psychol Sci Soc Sci. 2007;62:45-52.

32. Colcombe SJ, Erickson KI, Scalf PE, et al. Aerobic exercise training increases brain volume in aging humans. J Gerontol A Biol Sci Med Sci. 2006;61:1166-1170.

33. Boyke J, Driemeyer J, Gaser C, Büchel C, May A. Training-induced brain structure changes in the elderly. J Neurosci. 2009;28:7031-7035.

34. Lövdén $M$, Schaefer $S$, Noack $H$, et al. Spatial navigation training protects the hippocampus against age-related changes during early and late adulthood. Neurobiol Aging. 2012;33:620.e9-620.e22.

35. Noack $H$, Lövdén $M$, Schmiedek F, Lindenberger U. Cognitive plasticity in adulthood and old age: gauging the generality of cognitive intervention effects. Restor Neurol Neurosci. 2009; 27:435-453.
36. Brehmer $Y$, Rieckmann A, Bellander $M$, Westerberg $H$, Fischer $H$, Bäckman L. Neural correlates of training-related working-memory gains in old age. Neurolmage. 2011;58:1110-1120.

37. Carlson MC, Erickson $\mathrm{KI}$, Kramer AF, et al. Evidence for neurocognitive plasticity in at risk older adults: the experience corps program. J Gerontol A Biol Sci Med Sci. 2009;64:1275-1282.

38. Mozolic JL, Hayasaka S, Laurienti PJ. A cognitive training intervention increases resting cerebral blood flow in healthy older adults. Front Hum Neurosci. 2010;12;4-16.

39. Lövdén $M$, Brehmer $Y$, Li S, Lindenberger U. Training-induced compensation versus magnification of individual differences in memory performance. Front Hum Neurosci. 2012;6:141.

40. Jones S, Nyberg L, Sandblom J, et al. Cognitive and neural plasticity in aging: general and task-specific limitations. Neurosci Biobehav Rev. 2006:30:864-871.

41. Willis SL, Nesselroade CS. Long-term effects of fluid ability training in old-old age. Dev Psychol. 1990;26:905-910.

42. Ball K, Berch DB, Helmers KF, et al. Advanced Cognitive Training for Independent and Vital Elderly Study Group. Effects of cognitive training interventions with older adults: a randomized controlled trial. JAMA. 2002;288:2271-2281.

43. Willis SL, Tennstedt SL, Marsiske M, et al. Long-term effects of cognitive training on everyday functional outcomes in older adults. JAMA. 2006:296:2805-2814.

44. Loosli SV, Buschkuehl M, Perrig WJ, Jaeggi SM. Working memory training improves reading processes in typically developing children. Child Neuropsychol. 2012;18:62-78.

45. Dahlin E, Nyberg L, Bäckman L, Neely, AS. Plasticity of executive functioning in young and older adults: immediate training gains, transfer and long-term maintenance. Psychol Aging. 2008;23:720-730.

46. Mahnke HW, Connor BB, Appelman J, et al. Memory enhancement in healthy older adults using a brain plasticity-based training program: a randomized, controlled study. Proc Natl Acad Sci. 2006;103:12523-12528.

47. Randolph C, Tierney MC, Mohr E, Chase TN. The Repeatable Battery for the Assessment of Neuropsychological Status (RBANS): preliminary clinical validity. J Clin Exp Neuropsychol. 1998;20:310-319.

48. Zelinski EM, Spina LM, Yaffe K, et al. Improvement in memory with plasticity-based adaptive cognitive training: results of the 3-month followup. J Am Geriatr Soc. 2011;59:258-265.

49. NIH State-of-the-Science Conference Preventing Alzheiner 's Disease and Cognitive Decline. Available at: http://consensus.nih. gov/2010/docs/ alz/ALZ Final Statement.pdf (1-19). Accessed November 22, 2012.

50. Martinez IL, Frick K, Glass TA, et al. Engaging older adults in high impact volunteering that enhances health: recruitment and retention in The Experience Corps Baltimore. J Urban Health. 2006;83:941-953.

51. Stine-Morrow EA, Parisi JM, Morrow DG, Greene J, Park DC. An engagement model of cognitive optimization through adulthood. J Gerontol B Psychol Sci Soc Sci. 2007;62:62-69.

52. Stine-Morrow EA, Parisi JM, Morrow DG, Park, DC. The effects of an engaged lifestyle on cognitive vitality: a field experiment. Psychol Aging. 2008;23:778-786.

53. Stine-Morrow EA, Basak C. Cognitive interventions. In: Schaie KW, Willis SL, eds. Handbook of the Psychology of Aging. 7th ed. 2011;153-165.

54. Jackson JJ, Hill PL, Payne BR, Roberts BW, Stine-Morrow EA. Can an old dog learn (and want to experience) new tricks? Cognitive training increases openness to experience in older adults. Psychol Aging. 2012;27:286292.

55. Lodi-Smith J, Park DC. Synapse: A clinical trial examining the impact of actively engaging the aging mind. In: Hartman-Stein PE, LaRue $A$, eds. Enhancing Cognitive Fitness in Adults: A Guide to the Use and Development of Community-Based Programs. New York, NY: Springer; 2011. 